\begin{abstract}
The aim of the current study was to examine the reliability and validity of the Effects of Meditation (EOM) scale (Reavley \& Pallant, 2009). The Effects of Meditation scale consists of two sections: Experiences During Meditation (EOM-DM) and the Effects of Meditation in Everyday Life (EOM-EL). Adult meditators recruited online, completed questionnaires on the effects of meditation, compassion towards self and others, flow, satisfaction with life, and psychological distress. Confirmatory factor analysis was used to assess the factor structure and reliability of the EOM scales in an independent sample of adult meditators $(\mathrm{N}=254)$. A shortened 18-item version of the EOM-DM scale replicated the five-factor structure of the original 29-item scale. The seven-factor structure of the EOM-EL was not confirmed, with data revealing a single-factor EOMEL scale. The validity of the scales was also assessed. Individuals reporting greater cognitive, mystical and fewer negative emotions during meditation and in everyday life reported greater self-compassion, flow and less psychological distress and more benefits from meditation in everyday life than individuals less engaged during meditation.
\end{abstract}

Keywords: Meditation, Effects of Meditation Scale, mindfulness, flow, self compassion 


\section{An Examination of the Factor Structure of the Effects of Meditation Scale}

Meditation is widely accepted as an effective method to reduce physical and mental health problems and also to enhance well-being (Manocha, Black, \& Wilson, 2012). Furthermore, it is increasingly being incorporated as a therapeutic tool for selfregulation throughout Western psychology. However, despite the positive effects associated with meditation practice, an important area has largely been neglected within the field, this being the development of reliable and valid measures to assess meditation practice (Sedlmeier et al., 2012). Indeed there is a scarcity of measurement tools that have been specifically designed to measure the effects of meditation (Sedlmeier et al., 2012). The aim of the current study was to conduct a psychometric investigation on one such measure of meditation; the Effects of Meditation (EOM) scale (Reavley \& Pallant, 2009).

\subsection{Meditation}

Although there is no consensus in the literature on a general definition of meditation, most definitions share a common element relating to controlling attention. For example, meditation has been defined as the intentional self-regulation of attention from moment to moment (Kabat-Zinn, 1982) and as a set of self-regulation practices that aim to bring mental processes under voluntary control through focusing on attention and awareness (Walsh \& Shapiro, 2006).

According to Duerr (2004), meditation is now one of the most widely used and researched psychological tools worldwide. Over the past twenty years there has been a substantial increase in Western clinical interventions that use meditation skills, such as Acceptance and Commitment Therapy (ACT; Hayes, Strosahl, \& Wilson, 1999), Dialectical Behaviour Therapy (DBT; Linehan, 1993) and Mindful Self-Compassion (MSC; Neff \& Germer, 2013). Other health professionals are also positive towards the use of meditation. Results from a national survey of 636 Australian General 
Practitioners showed that $65 \%$ had recommended the use of meditation to their patients in the course of their practice over the previous twelve months (Cohen, Penman, Pirotta, \& De Costa, 2005).

In psychological practice, the benefits of meditation as a self-regulatory strategy in addressing an individual's mental health concerns or enhancing their wellbeing have been of therapeutic focus (Shapiro, 1992; Zaleski, 2010). Within the positive psychology framework, meditation has also been used as a tool to enhance the well-being of healthy individuals without any self-reported psychopathology (Zaleski, 2010). However, despite the numerous scientific meditation studies over the past four decades, meditation research still has a number of methodological problems, including a lack of assessment tools that accurately assess the meditation experience and its effects (Sedlmeier et al., 2012). This issue reduces the reliability and generalisability of research findings, which consequently limits the use of meditation as a clinical tool.

\subsection{Measurement of meditation.}

A review conducted by the Agency for Healthcare Research and Quality (AHRQ) reviewed 813 meditation studies to provide a detailed overview of the therapeutic use of meditation practices. Overall, the review found the methodological quality of meditation research was poor, concluding that poor measurement was the major issue impeding reliability and validity of this type of research (Ospina et al. 2007). Furthermore, a recent meta-analysis reported significant methodological problems across studies in this field (Sedlmeier et al., 2012). One of the major problems identified by the authors was that meditation studies typically utilize conventional questionnaires and tests that have not been specifically designed to measure the meditation experience. For the future of meditation research it is essential that the reliability and validity of measures that are specifically designed to assess the effects of meditation be improved. 
For the few meditation questionnaires that have been designed (e.g. Piron, 2001), these have not been widely used or validated (Reavley \& Pallant, 2009). In addition, common instruments used to assess the meditation experience were designed to measure mindfulness, such as the Freiburg Mindfulness Inventory (FMI; Buchheld, Grossman, \& Walsh, 2001) or the Mindful Attention Awareness Scale (MAAS; Brown \& Ryan, 2003). Although these scales can assess some aspects of the therapeutic effects of meditation, they do not include all facets of the meditation construct (Reavley \& Pallant, 2009). In addition, Bergomi, Tschacher, and Kuper (2012) assessed all the available self-report scales of mindfulness and concluded that these scales do not provide a comprehensive assessment of mindfulness in samples from the general population.

A recently developed scale, the Effects of Meditation (EOM) scale (Reavley \& Pallant, 2009) attempts to address these shortfalls by assessing the meditation experience more broadly. The instrument assesses the physical, emotional, and spiritual effects of meditation, which takes a more complete view of meditation than current mindfulness measures. This is the first scale developed to generally assess the effects of meditation. The preliminary study that developed the scale shows promising reliability and validity, but further independent evaluation and refinement of the scale is needed to develop its strength as an effective meditation measure. There is also a need for further validation of the scale with a wider variety of outcome indicators. The external validity of the measure would be supported through the prediction of known related constructs, such as flow, self-compassion, compassionate love for humanity, satisfaction with life, and psychological distress. This examination of the scale's validity thereby provides an extension to the work of Reavley \& Pallant (2009). Independent evaluation and validation of the scale is imperative in determining the 
STRUCTURE AND VALIDITY OF THE EOM

empirical support for the scale. The present study provides an important contribution to determining this support, and to promoting methodological rigour within this field.

\subsection{The Current Study}

The aim of the current study was to conduct an independent assessment of the psychometric properties of the EOM, as it relates to the effects of meditation during meditation (EOM-DM) and in everyday life (EOM-EL). It was predicted that the 5factor structure of the EOM-DM scale and the 7-factor structure of the EOM-EL scale would be confirmed, supporting the original findings of Reavley and Pallant (2009). The validity of the EOM scale was also of interest and was examined by exploring the relationship between the EOM-DM and EOM-EL scales and related outcomes. It was expected that the factors on the EOM-DM scale would positively predict scores in self-compassion, compassionate love for humanity, flow, satisfaction with life and negatively predict psychological distress. Furthermore, it was predicted that the EOMEL scale would be positively associated with self-compassion, compassionate love for humanity, flow and satisfaction with life, and negatively associated with psychological distress.

\section{Method}

\subsection{Participants}

Participants were 254 individuals currently practicing meditation. Ages of participants ranged from 20 to 91 years $(M=47.65$ years; $S D=12.62)$, with 139 (54.7\%) female. Participants predominantly identified as Caucasian (81.8\%), were married/defacto (60.5\%), tertiary educated (75.5\%), employed (75.2\%), and mostly identified their religion and/or spirituality as ‘None’ (26.3\%), Buddhist (15.4\%) or Christian (10.1\%).

Meditation practice of participants ranged from 2 months to 80 years, with 9.1\% reporting meditating for two years or less; $15.4 \%$ reported meditating for two to 
five years, $20.6 \%$ between 5 and 10 years, 22.1\% between 10 and 20 years, with the remaining $32.8 \%$ meditating for more than 20 years. There were $59.4 \%$ of the sample who reported meditating every day for between 5 and 360 minutes. The main types of meditation participants practiced were mindfulness type meditations (35.6\%) and concentrative type meditations (42.7\%).

\subsection{Measures}

2.2.1. Demographic information concerning age, gender, ethnicity, marital status, education level, employment status, religious/spiritual beliefs and meditation practice were obtained.

2.2.2. EOM (Reavley \& Pallant, 2009). The EOM self-report scale measures the effects of meditation while meditating (29 items; EOM-DM) and in everyday life (35 items; EOM-EL). The originally developed EOM-DM has five subscales (Table

1). For each item, participants respond using a 6-point scale from 1 (almost never) to 6 (almost always). The EOM-EL has seven subscales (Table 1). Participants respond to a 6-point scale from 1 (not true for me) to 6 (true for me).

Table 1

Experience of meditation scale (Reavley \& Pallant, 2009)

Experience of meditation - during meditation (EOM-DM)

$\begin{array}{lll}\text { Subscales } & \text { Example Items alpha }(\alpha)\end{array}$

\begin{tabular}{lll}
\hline $\begin{array}{l}\text { Cognitive effects (8 items) } \\
\text { High score: more positive effects }\end{array}$ & $\begin{array}{l}\text { 'I observe my thoughts as an } \\
\text { impartial observer' }\end{array}$ & .87 \\
'My mind is alert and still' & \\
Emotional effects ( 6 items) & $\begin{array}{l}\text { 'I experience fluctuating emotions' } \\
\text { 'I experience feelings of tension and anxiety' }\end{array}$ & .86 \\
$\begin{array}{l}\text { Mystical experiences (5 items) } \\
\text { High score: more positive effects }\end{array}$ & $\begin{array}{l}\text { 'I have an experience of contact with a higher power a sense of awe and wonder' } \\
\text { Relaxation (5 items) }\end{array}$ & .86 \\
$\begin{array}{l}\text { High score: more positive effects } \\
\text { Physical discomfort (5 items) }\end{array}$ & $\begin{array}{l}\text { 'My body becomes heavy' } \\
\text { 'I am aware of physical discomfort' } \\
\text { High score: less positive effects }\end{array}$ & .68 \\
\hline
\end{tabular}

Experience of meditation - everyday life (EL).

$\begin{array}{lll}\text { Subscales } & \text { Example items } & \text { alpha }(\alpha)\end{array}$

\begin{tabular}{lll}
\hline Physical & 'I have more energy or vitality’ & .83
\end{tabular}




\begin{tabular}{|c|c|c|}
\hline Emotional & $\begin{array}{l}\text { 'I am less anxious' } \\
\text { 'I am less depressed' }\end{array}$ & .87 \\
\hline Expanded & 'I experience more fulfilment and meaning in life' & .87 \\
\hline consciousness & 'I feel a sense of inner peace and strength' & \\
\hline Social relations & $\begin{array}{l}\text { "I have less conflict with others' } \\
\text { 'I am more compassionate and empathic' }\end{array}$ & .89 \\
\hline Cognitive ability & $\begin{array}{l}\text { 'I have better mental focus and concentration' } \\
\text { 'My memory is better' }\end{array}$ & \\
\hline $\begin{array}{l}\text { Non-judgemental } \\
\text { acceptance }\end{array}$ & $\begin{array}{l}\text { 'I am less judgemental of myself and others' } \\
\text { 'I am able to forgive myself and others and move on' }\end{array}$ & \\
\hline Behaviours and habits & $\begin{array}{l}\text { ''I have less destructive behaviour' } \\
\text { 'I am less affected by strong desires or impulses' }\end{array}$ & \\
\hline
\end{tabular}

2.2.3. Self-Compassion Scale (SCS; Neff, 2003). The SCS has 26-items that assess different aspects of self-compassion, including mindfulness. Participants responded to items using a 5-point scale extending from 1 (almost never) to 5 (almost always), with higher total scores indicating greater self-compassion. The scale has good internal consistency (.92) and test-retest reliability (Neff, 2003). Internal consistency in this study was .76.

2.2.4. Compassionate Love Scale (CLS; Sprecher \& Fehr, 2005). The CLS has 42 items that measure compassion for others. Half the items measure compassion toward close others such as family and friends and the other half refers to strangers or all of humanity. Item responses are made using a seven-point scale extending from 1 (not at all true of me) to 7 (very true of me). Higher total scores indicate greater compassion toward others. Internal consistency is .95 (Sprecher \& Fehr, 2005), and was also .95 in the current study.

2.2.5. Dispositional flow scale (DFS-2; Jackson \& Eklund, 2002). The DFS is a 36-item measure used to assess how often individuals report experiencing flow while undertaking an activity important to them. Item responses are made using a 5point scale extending from 0 (Never) to 5 (Always). Higher total scale scores identify individuals more likely to experience flow. Internal consistency is .90 (Jackson \& Ekland, 2002) and in the current study .96. 


\subsubsection{Satisfaction with Life Scale (SWLS; Diener, Emmons, Larsen \&}

Griffin, 1985). The SWLS measures global life satisfaction as a cognitive-judgmental process. There are 5 items, measured on a 7-point scale extending from 1 (strongly disagree) to 7 (strongly agree). The scale has good internal consistency (.87; Diener et al., 1985), temporal stability, and convergent validity with related measures such as happiness (e.g. Compton, Smith, Cornish, \& Qualls, 1996; Pavot \& Diener, 1993). Internal consistency in this study was .85.

\subsubsection{Outcome Questionnaire (OQ45; Lambert, Lunnen, Umphress,} Hansen, \& Burlingame, 1994). The OQ45 is a 45 item measure of psychological distress. Responses to items in three domains (symptom distress, problems in interpersonal relationships, and problems in social role performance) are made on a 5point scale extending from 0 (never) to 4 (almost always). Higher scores on the total scale indicate greater psychological distress. Reported internal consistency .93 and test-retest reliability of .84 have been obtained (Kadera, Lamber, \& Andrews, 1996; Umphress, Lambert, Smart, \& Barlow, 1997). Internal consistency in this study was .91 .

\subsection{Procedure}

Institutional ethics approval was obtained. Participants were recruited through meditation websites, and responded to the survey online. Participants were instructed that meditation referred to formal meditation practice, which was described as: 'when you purposefully sit for meditation, or when you set a specific time aside to practice your meditation technique'. On other measures responses were based on current thought and experiences.

\section{Results}

\subsection{Effects of Meditation Scale - Experiences During Meditation (EOM-DM)}


Data analyses for the confirmatory factor analysis (CFA) were conducted with AMOS Version 22. Missing data was found to be missing completely at random for all variables using Littles chi-square test (Little \& Rubin, 2002). A maximum likelihood procedure was used to estimate missing data points. Two CFA models were produced. The first model aimed to confirm the original five-factor structure using the original 29-items (Reavley \& Pallant, 2009). The second model aimed to evaluate a shorter more parsimonious measure, which used the same five-factor structure (see Table 2). The models were generated using the maximum likelihood estimation procedure. Model fit was assessed using the $\chi^{2}$ statistic to test the absolute fit of the model, and the Comparative Fit Index (CFI) to test the incremental fit of the model, and the Root Mean Square Error of Approximation (RMSEA; Byrne, 2010) to estimate error due to the approximate fit of the model. A $\chi^{2}$ value two to three times greater than the degrees of freedom was considered acceptable (Jackson, Gillaspy, \& Purc-Stephenson, 2009). The $\chi^{2}$ and CFI indices compare the specified model to one with complete independence: a non-significant $\chi^{2}$ and CFI values greater than .9 to .95 reflect a good model fit. RMSEA values below .08 were deemed to reflect good model fit (Jackson et al., 2009).

The items comprising the five factors were allowed to load freely on separate latent factors, with the correlations among the five latent variables also freely estimated. The fit statistics for this analysis were less than satisfactory, $\chi^{2}(289)=$ 767.72, $p<.001, \chi^{2} / \mathrm{df}=2.65, \mathrm{GFI}=.80, \mathrm{CFI}=.80, \mathrm{RMSEA}=.081(\mathrm{PCLOSE}<$ .001), indicating a poor fit for this model.

In the modified model there were three items included in each of the relaxation and physical discomfort factors. There were four items retained on the mystical experience, cognitive factors and emotional effects subscales. Items were selected based on the factor loadings of the items on each factor from the original analysis (see 
Table 2). For the 5-factor modified model the fit statistics were, $\chi^{2}(125)=260.74, p<$ $.001, \chi^{2} / \mathrm{df}=2.08, \mathrm{GFI}=.90, \mathrm{CFI}=.91, \mathrm{RMSEA}=.06(95 \% \mathrm{CI} .05-.07)(\mathrm{PCLOSE}=$ .013), indicating an acceptable fit. All items loaded significantly on their respective latent variables (range $=.45$ to .78 ). With the exception of the relaxation subscale, the internal consistency of all scales was acceptable (Table 3).

Consistent with Reavley and Pallant (2009), few correlations were found between subscales (Table 3). Increased cognitive effects were associated with greater mystical experiences and better relaxation. Reports of greater physical discomfort was associated with reports of greater emotional distress during meditation.

Table 2

Factor loadings for items included in model 1 and model $2(N=254)$

\begin{tabular}{lcc}
\hline & Model 1 & Model 2 \\
EOMS-DM Factors & Factor & Factor \\
& Loadings & Loadings \\
\hline
\end{tabular}

Factor 1 - Cognitive effects

I observe without judgement any positive thoughts or emotions that arise

I observe without judgement any negative thoughts or emotions that arise

I observe my thoughts as an impartial observer

I accept my meditation practice however it is going

I experience feelings of gratitude and contentment

I am able to let my thoughts go and not get caught up in them

My mind is alert and still

My perceptions are clearer

\section{Factor 2 - Mystical experiences}

I have an experience of contact with a higher power

I have what I describe as a mystical experience

I experience what are sometimes described as psychic phenomena

I have a new awareness of the order in the universe

I feel a sense of awe and wonder

Loadings

\section{Factor 3 - Relaxation}

I feel my breathing slow down $\quad .69$

My body becomes heavy $\quad .11$

I feel my heart rate slow down $\quad .67$

My body becomes soft and loose

My body awareness changes as if parts of it were missing or 
I experience feelings of anger

\section{Factor 5 - Physical discomfort}

I am aware of physical discomfort

I feel restless or twitching of parts of my body

I feel the desire to scratch, sneeze, scratch or swallow $\quad .12$

I become aware of tightness in parts of my body $\quad .60$

I feel the desire to smile or laugh

! Due to the high correlations between the two thought questions one of these was excluded from the final model

Table 3

EOM-DM descriptive statistics and correlations $(N=254)$

\begin{tabular}{lccccccc}
\hline EOMS-DM Factors & F1 & F2 & F3 & F4 & F5 & M & SD \\
\hline F1 - Cognitive $(\alpha=77)$ & - & $.48^{* * *}$ & $.52^{* * *}$ & -.09 & $-.25^{*}$ & 4.55 & 0.96 \\
F2 - Mystical $(\alpha=83)$ & & - & $.41^{* * *}$ & -.11 & -.09 & 3.62 & 1.32 \\
F3 - Relaxation $(\alpha=.68)$ & & & - & -.02 & -.07 & 4.40 & 1.05 \\
F4 - Physical $(\alpha=.73)$ & & & & & $.54 * * *$ & 2.73 & 1.11 \\
F5 - Emotion $(\alpha=.75)$ & & & & & - & 1.97 & 0.82
\end{tabular}

$* p<.05 ; * * \mathrm{p}<.01 ; * * * \mathrm{p}<.001$

\subsection{Effects of Meditation Scale - Experiences in Everyday Life (EOM-EL)}

Investigation of the items on the EOM-EL scale revealed there was significant negative skew in all items on the scale, making it unsuitable for CFA (Jackson, et al., 2009). An exploratory factor analysis was conducted in which four factors were extracted with an eigenvalue greater than one, overall accounting for $70 \%$ of the variance in the solution. However, Factor 1 accounted for $57.1 \%$ of the variance, with all items achieving a factor loading of .63 or greater, indicating a unidimensional construct. Follow-up parallel analysis (O’Connor, 2000) produced evidence of two factors in the solution. However, of the 35 items, 20 (57\%) had loadings on both factors of .4 or greater. On this basis a total score was obtained for the Effects of Meditation in Everyday Life scale only. Coefficient alpha for the overall scale was .97, also evidence that the measure in the current sample was assessing a single construct. 


\subsection{Construct Validity}

Total scores for each of the subscales of the EOM-DM and a total score using all items on the EOM-EL scales were generated. Correlations between each of the scales and measures of psychological distress, self-compassion, compassionate love for humanity, life satisfaction, flow and experience of meditation variables are shown in Table 4.

Table 4

Correlations between EOM-DL subscales, EOM-EL total, meditation experience and psychological variables.

\begin{tabular}{|c|c|c|c|c|c|c|}
\hline Variables & $\begin{array}{l}\text { EOM-DL } \\
\text { Cognitive }\end{array}$ & Mystical & Relaxation & Physical & Emotional & $\begin{array}{l}\text { EOM-EL } \\
\text { Everyday }\end{array}$ \\
\hline $\begin{array}{l}\text { Minutes } \\
\text { meditating }\end{array}$ & $.13^{*}$ & .080 & .065 & -.042 & -.065 & $.17^{*}$ \\
\hline $\begin{array}{l}\text { Experience } \\
\text { (years) }\end{array}$ & $.213^{* *}$ & $.255^{* * *}$ & .094 & $-.156^{*}$ & $-.135 *$ & .108 \\
\hline $\begin{array}{l}\text { Everyday } \\
\text { Psychological } \\
\text { variables }\end{array}$ & $.497 * * *$ & $.473 * * *$ & $.396 * * *$ & $-.151 *$ & $-.242 * * *$ & \\
\hline $\begin{array}{l}\text { Psychological } \\
\text { distress }\end{array}$ & $-.447 * * *$ & $-.264 * * *$ & $-.290 * * *$ & $.349 * * *$ & $.495^{* * *}$ & $-.485 * * *$ \\
\hline $\begin{array}{l}\text { Compassion } \\
\text { others }\end{array}$ & $.314^{* * *}$ & $.483 * * *$ & $.430 * * *$ & -.071 & -.025 & $.444^{* * *}$ \\
\hline $\begin{array}{l}\text { Self- } \\
\text { compassion }\end{array}$ & $.474 * * *$ & $.363^{* * *}$ & $.344 * * *$ & -.214 & $-.301 * * *$ & $.518^{* * *}$ \\
\hline Flow & $.628 * * *$ & $.459 * * *$ & $.524 * * *$ & -.156 & $-.301 * * *$ & $.541 * * *$ \\
\hline $\begin{array}{l}\text { Life } \\
\text { satisfaction }\end{array}$ & $.259 * * *$ & $.302 * * *$ & $.262 * * *$ & $-.205^{* *}$ & -.206 & $.420 * * *$ \\
\hline
\end{tabular}

Pearson correlations between the EOM scales and meditation experience were weak or non-significant. Reduced psychological distress and increased selfcompassion, compassionate love for humanity, flow and life satisfaction were associated with reports of greater cognitive and mystical experiences and increased relaxation during meditation. Reports of greater physical discomfort and more negative emotion during meditation were associated with reports of increased psychological distress, and reduced self-compassion, flow and life satisfaction. Reports of greater benefit of meditation in everyday life was associated with reduced psychological distress and greater self-compassion, compassionate love for humanity, greater flow and increased life satisfaction. 
A series of standard multiple linear regression analyses were conducted to determine the ability of the five EOM-DM subscales (cognitive effects, emotional effects, mystical experiences, relaxation and physical discomfort) to explain variance in predicted meditation outcomes (compassionate love for humanity, self-compassion, flow, satisfaction with life and psychological distress). After exclusion of two cases with extreme scores, the assumptions of the regression analyses were met.

The subscales accounted for $30.2 \%$ of the variance in self-compassion, $F(5$, 246) $=21.24, p<.001$. Significant unique contributions to the explanation were made by cognitive $(\beta=.289, p<.001)$, mystical $(\beta=.159, p=.012$ and emotional $(\beta=-.171$, $p=.010$ ) impacts during meditation (see Table 5). Higher scores on the cognitive and mystical effects subscales and lower scores on the emotional effects subscale were associated with greater self-compassion scale.

Table 5

Unique Contributions of the Subscales of EOM-DM Scale When Explaining Variance in Self-compassion $(N=252)$ and compassionate love $(N=252)$.

\begin{tabular}{lllll}
\hline \multirow{2}{*}{ Subscale } & \multicolumn{2}{l}{ Self Compassion } & \multicolumn{2}{c}{ Compassionate Love } \\
\hline Cognitive effects & $.044(.01)$ & $.289^{* * *}$ & $.579(.35)$ & .120 \\
Mystical experiences & $.017(01)$ & $.159^{*}$ & $1.48(.23)$ & $.420^{* * *}$ \\
Relaxation & $.021(.01)$ & .114 & $.052(.40)$ & .001 \\
Physical discomfort & $-.013(.01)$ & -.077 & $-.22(.37)$ & -.039 \\
Emotional effects & $-.030(.01)$ & $-.171^{*}$ & $.271(.39)$ & .700 \\
\hline \multirow{2}{*}{${ }^{*}<<.05 ; * * *=p<.01 ; R^{2}$ (self-compassion) $=.302 ; R^{2}$ (compassionate love $)=.245}$.
\end{tabular}

The subscales explained $24.5 \%$ of the variance in compassionate love for humanity, $F(5,246)=15.94, p<.001$. A significant unique contribution was made by mystical experiences $(\beta=0.420, p<.001)$ only. Higher scores on the mystical experiences subscales are associated with reports of greater compassionate love for humanity (Table 5). 
The EOM subscales explained $16.5 \%$ of the variance in life satisfaction, $F(5$, 246) $=9.67, p<.001$. Significant unique contributions were made by mystical experiences $(\beta=.204, p=.003)$, relaxation $(\beta=.141, p=.046)$, and emotional effects $(\beta=-.155, p=.032)$. Better life satisfaction was associated with reports of higher level mystical experience, better relaxation and less emotional difficulties during meditation (Table 6).

Table 6

Unique contributions of the subscales of EOM-DM scale when explaining variance in satisfaction with life $(N=252)$ and psychological distress $(N=252)$

\begin{tabular}{|c|c|c|c|c|}
\hline \multirow[b]{2}{*}{ Subscale } & \multicolumn{2}{|c|}{ Satisfaction with life } & \multicolumn{2}{|c|}{ Psychological Distress } \\
\hline & $B(S E)$ & $\beta$ & $B(S E)$ & $\beta$ \\
\hline Cognitive effects & $.056(.10)$ & .042 & $-1.27(.30)$ & $-.267^{* * *}$ \\
\hline Mystical experiences & $.198(.07)$ & $.204^{*}$ & $-.218(.20)$ & -.063 \\
\hline Relaxation & $.230(.12)$ & $.141^{*}$ & $-.573(.35)$ & -.009 \\
\hline Physical discomfort & $-.142(.11)$ & -.093 & $.700(.33)$ & $.129 *$ \\
\hline Emotional effects & $-.241(.11)$ & $-.155^{*}$ & $1.92(.34)$ & $.35 * * *$ \\
\hline
\end{tabular}

${ }^{*} p<.05 ; * * *=p<.01 ; R^{2}$ (satisfaction with life $)=.165 ; R^{2}$ (psychological distress) $=$ .348 .

The subscales accounted for $38.4 \%$ of the variance in psychological distress, $F(5,246)=30.70, p<.001$. Significant unique contributions were made by cognitive $(\beta=-.267, p<.001)$, physical discomfort $(\beta=.129, p=.032)$ and emotional effects $(\beta=$ $.350, p<.001)$. Reports of reduced cognitive effects, greater physical discomfort and more negative emotion during meditation were associated with higher psychological distress (Table 6).

Finally, the subscales explained $49.4 \%$ of the variance in flow, $F(5,244)=$ 47.66, $p<.001$ (Table 7). Significant unique contributions were made by cognitive $(\beta$ $=.377, p<.001$, mystical experiences $(\beta=.169, p=.002)$, relaxation $(\beta=.241, p<.001)$ and emotional effects $(\beta=-.174, p=.002)$. Increased flow was associated with greater 
cognitive effects, more mystical experiences, greater relaxation and fewer negative emotions during meditation.

Table 7

Unique contributions of the subscales of EOM-DM scale when explaining variance in flow $(N=250)$

\begin{tabular}{lll}
\hline Subscale & \multicolumn{1}{l}{ Flow } & \\
\hline Cognitive effects & $B(S E)$ & \multicolumn{1}{c}{$\beta$} \\
Mystical experiences & $1.89(.29)$ & $.377^{* * *}$ \\
Relaxation & $.615(.19)$ & $.169^{* *}$ \\
Physical discomfort & $1.48(.34)$ & $.241^{* * *}$ \\
Emotional effects & $-.057(.32)$ & -.180 \\
& $-1.01(.33)$ & $-.174^{* *}$ \\
\hline${ }^{*}<<.05 ; * * p<.01 ; * * *=p<.01 ; R^{2}$ (flow) $=.165 ; R^{2}$ (psychological distress) $=.494$.
\end{tabular}

In summary, greater cognitive benefits reported during meditation were uniquely associated with greater self-compassion, flow and reduced psychological distress. More mystical experiences during meditation were associated with increased self-compassion, compassionate love for humanity, life satisfaction and flow. Greater relaxation during meditation was associated with increased flow and greater life satisfaction. Fewer negative emotions during meditation were associated with increased self-compassion, greater life satisfaction and flow and reduced psychological distress. Reports of greater physical discomfort during meditation was associated with greater psychological distress only.

\section{Discussion}

The aim of the study was to examine the reliability and validity of the Effects of Meditation (EOM) scale (Reavley \& Pallant, 2009) with an independent sample of individuals who currently meditate.

\subsection{EOM-DM}

For the EOM-DM scale, the present findings did not replicate the original 29item five-factor model. However, a modified model was generated using the items in 
each subscale with high factor loadings. Items with lower factor loadings appeared to be ambiguous, or less relevant or unique to the experiences of meditators. The modified model replicated the factor structure of the original EOM-DM scale; Cognitive effects, Mystical experiences, Relaxation, Physical discomfort and Emotional effects. Each subscale showed adequate internal consistency with the exception of Relaxation. The Relaxation subscale also demonstrated the lowest internal consistency in the original validation study by Reavley and Pallant (2009), indicating that this subscale needs to be interpreted with caution.

The cognitive effects, mystical experiences and relaxation subscales were moderately correlated with each other and the physical discomfort scale was moderately correlated with the emotional effects subscale. All other correlations were weak, confirming that the subscales are predominantly measuring different components of experiences during meditation. This supports findings from Reavley and Pallant's (2009) original scale which found individual subscale scores best represented experiences of meditators during meditation rather than combining the subscales to form a total score. Although the Relaxation subscale may need revision in future research, the findings from the present study suggest that a shorter 18-item EOM-DM scale offers a more concise and refined scale.

A further aim of the study was to determine the construct validity of the scale by examining the relationship of the factors to existing validated measures of selfcompassion (SCS), compassionate love for humanity (CLS), flow (DFS-2), satisfaction with life (SWLS) and psychological distress (OQ45). As expected, the experiences of meditators during meditation were significantly correlated with all the measures examined. The cognitive effects subscale was most strongly correlated with reduced psychological distress, increased self-compassion and flow. The cognitive effects subscale was also the best predictor of scores on these measures. This is 
consistent with most definitions of meditation which describe meditation as having a cognitive element relating to the control of attention (Kabat-Zinn, 1982; Manocha, 2000; Walsh \& Shapiro, 2006).

Overall, the five meditation experience subscales accounted for $18-49 \%$ of the variance in the measures examined, with the variance in flow being the most highly accounted for by experiences during meditation. In the literature, meditational practice has been linked to flow experiences and both share a goal of attaining a state of full attentional control (Peifer, 2012). The current study supports that meditation is an activity where individuals experience flow, and possibly practicing meditation would lead to more flow in an individual's life.

\subsection{EOM-EL}

The current study also aimed to validate the structure of the EOM-EL in an independent sample. Present findings suggest that a single construct model is a better fit compared to the original seven-factor model. The single factor EOM-EL scale showed high internal consistency $(\alpha=.97)$. During the initial EOM-EL scale development Reavley and Pallant (2009) also had difficulty identifying a suitable factor solution from the original 65 items and their original parallel analysis only supported the retention of one factor. As such, the physical, emotional, expanded consciousness and cognitive/behavioural items were analysed separately to produce the 7-factors. However, the current study supports their first analysis that identified a single construct for the effects of meditation in everyday life.

One possible explanation for the present findings relates to the years of meditation experience of the current sample. More than half (54.9\%) of the sample had 10 years or more meditation experience compared to only $9 \%$ of the sample who had less than 2 years of experience. A meta-analysis by Sedlmeier et al. (2012) suggested that meditation effects only increase until 10 years of practice. Therefore, it 
is possible that the current sample were reporting similar positive effects of meditation in their everyday life. This might explain the significant negative skew of responses, which consequently made the CFA unsuitable to conduct.

As expected the EOM-EL scale was significantly correlated with all other measures examined. Similar to the EOM-DM scale, the EOM-EL scale was most strongly correlated with flow, further supporting a link between meditation and flow. Additionally, individuals reporting higher scores on the EOM-EL scale reported higher scores on the EOM-DM cognitive effects, mystical experience and relaxation subscales and lower scores on the emotional effects and physical discomfort subscales.

Overall, the present findings provide psychometric evidence to support the modified version of the Effects of Meditation scale being a useful tool to assess the effects of meditation, both during meditation (EOM-DM) and in everyday life (EOMEL). The current study has found that the 18-item five-factor EOM-DM scale and the single-factor EOM-EL scale are reliable and valid measures.

\subsection{Limitations of the study}

The current study results need to be considered within the methodological limitations of the design and the nature of the sample. Concerning the use of an online data collection tool, it is possible that internet users may vary from non-users on important demographic, social and psychological characteristics (Robinson, Neustadtl, \& Kestenbaum, 2002). The generalizability of the findings is further limited in that participants were primarily white, married, university educated and employed, which predominantly reflects people that live in a western culture. Given that most meditative practices originate from the East within a different cultural framework, it is possible that different results would be obtained in more culturally diverse samples.

\subsection{Implications and Future Research Directions}


Despite these limitations, this study is the first to replicate the reliability and validity of the Effects of Meditation scale (EOM-DM, EOM-EL; Reavley \& Pallant, 2009). This replication is an important step in independently evaluating the strength of the measure, and is hoped to encourage use of validated measures and increased methodological rigour within this field. Future research should assess the EOM's ability to identify differences in the effects of meditation for individuals who use different types of meditation, or who meditate for different reasons (e.g., selfregulation, self-liberation).

Meditation is a tool that is beneficial for a wide spectrum of society, and one that is being increasingly incorporated into psychological practice. Any further understanding of its effects and related outcomes will assist the broader community to implement meditation into their daily life to increase their level of health and wellbeing and to strive towards optimal functioning.

\section{References}

Bergomi, C., Tschacher, W., \& Kuper. Z. (2012). The assessment of mindfulness with self-report measures: existing scales and open issues. Mindfulness, 1-12.

Brown, K.W, \& Ryan, R.M. (2003). The benefits of being present: mindfulness and its role in psychological well-being. Journal of Personality and Social Psychology, 84(4), 822-848. 
STRUCTURE AND VALIDITY OF THE EOM

Buchheld, N., Grossman, P., \& Walsh, H. (2001). Measuring mindfulness in insight meditation (vipassana) and meditation-based psychotherapy: The development of the Freiburg mindfulness inventory (FMI). Journal for Meditation and Meditation Research, 1(1), 11-34.

Byrne, B. M. (2010). Structural equation modeling with AMOS: Basic concepts, applications and programming ( ${ }^{\text {nd }}$ Ed.). New York, NY: Routledge.

Cohen, M. M., Penman, S., Pirotta, M., \& Costa, C. D. (2005). The integration of complementary therapies in Australian general practice: results of a national survey. Journal of Alternative \& Complementary Medicine: Research on Paradigm, Practice, and Policy, 11(6), 995-1004.

Compton, W. C., Smith, M. L., Cornish, K. A., \& Qualls, D. L. (1996). Factor structure of mental health measures. Journal of Personality and Social Psychology, 71, 406-413.

Diener, E. D., Emmons, R. A., Larsen, R. J., \& Griffin, S. (1985). The satisfaction with life scale. Journal of personality assessment, 49(1), 71-75.

Duerr, M. (2004). A powerful silence: The role of meditation and other contemplative practices in American life and work. Northampton, MA: Center for Contemplative Mind in Society.

Hayes, S. C., Strosahl, K., \& Wilson, K. G. (1999). Acceptance and commitment therapy. New York: Guilford Press.

Jackson, S. A., \& Eklund, R. C. (2002). Assessing flow in physical activity: The flow state scale-2 and dispositional flow scale-2. Journal of Sport and Exercise Psychology, 24, 33-150. 
Jackson, D. L., Gillaspy Jr, J. A., \& Purc-Stephenson, R. (2009). Reporting practices in confirmatory factor analysis: an overview and some recommendations. Psychological methods, 14(1), 6.

Kabat-Zinn, J. (1982). An outpatient program in behavioral medicine for chronic pain patients based on the practice of mindfulness meditation: Theoretical considerations and preliminary results. General Hospital Psychiatry, 4, 3-47.

Kadera, S. W., Lambert, M. J., \& Andrews, A. A. (1996). How much therapy is really enough: A session-by-session analysis of the psychotherapy dose-effect relationship. Journal of Psychotherapy Practice and Research, 5, 132-151.

Lambert, M. J., Lunnen, K., Umphress, V., Hansen, N. \& Burlingame, G. M. (1994). Administration and scoring manual for the Outcome Questionnaire (OQ-45.1). Salt Lake City: IHC Center for Behavioral Healthcare Efficacy.

Linehan, M. (1993). Cognitive-behavioral therapy of borderline personality disorder. New York: Guilford Press.

Little, R.J. \& Rubin, D.B. (2002). Statistical analysis with missing data. New York: Wiley.

Manocha, R. (2000). Why meditation. Australian Family Physician, 29, 1135-8.

Manocha, R., Black, D., \& Wilson, L. (2012). Quality of life and functional health status of long-term meditators. Evidence-Based Complementary and Alternative Medicine, 2012.

Neff, K. D. (2003). The development and validation of a scale to measure selfcompassion. Self and Identity, 2(3), 223-250.

Neff, K. D., \& Germer, C. K. (2013). A Pilot Study and Randomized Controlled Trial of the Mindful Self-Compassion Program. Journal of clinical psychology,69 (1), 28-44. 
STRUCTURE AND VALIDITY OF THE EOM

O'Connor, B. P. (2000). SPSS and SAS programs for determining the number of components using parallel analysis and Velicer's MAP test. Behavior Research Methods, Instrumentation, and Computers, 32, 396-402

Ospina, M.B., Bond, K., Karkhaneh, M., Tjosvold, L., Vandermeer, B., Liang, Y., et al. (2007). Meditation Practices for Health: State of the Research. (for the University of Alberta Evidence-based Practice Center). AHRQ Publication No. 07-E010, 2007.

Pavot, W., \& Diener, E. (1993). Review of the satisfaction with life scale. Psychological assessment, 5(2), 164.

Peifer, C. (2012). Psychophysiological correlates of flow-experience. In Advances in flow research (pp. 139-164). Springer New York.

Piron, H. (2001). The meditation depth index (MEDI) and the meditation depth questionnaire (MEDEQ). Journal for Meditation and Meditation Research, 1(1), 69-92.

Reavley, N. \& Pallant, J.F. (2009). Development of a Scale to Assess the Meditation Experience. Personality and Individual Differences, 47, 547-552.

Robinson, J. P., Neustadtl, A., \& Kestenbaum, M. (2002). Why public opinion polls are inherently biased: Public opinion differences among Internet users and nonusers. In annual meeting of the American Association for Public Opinion Research, St. Petersburg Beach, FL.

Sedlmeier, P., Eberth, J., Schwartz, M., Zimmermann, D., Haarig, F., Jaeger, S. \& Kunze, S. (2012). The Psychological Effects of Meditation: A Meta-Analysis. Psychological Bulletin, Vol. 138, No. 6, 1139-1171.

Shapiro, D.H. (1992). A Preliminary Study of Long-term Meditators: Goals, Effects, Religious Orientation, Cognitions. The Journal of Transpersonal Psychology, Vol. 24, No. 1, 23-39. 
Sprecher, S., \& Fehr, B. (2005). Compassionate love for close others and humanity. Journal of Social and Personal Relationships, 22, 629-651.

Umphress, V. J., Lambert, M. J., Smart, D. W. \& Barlow, S. H. (1997). Concurrent and construct validity of the outcome questionnaire. Journal of Psychoeducational Assessment, 15, 40-55.

Walsh, R., \& Shapiro, S.L. (2006). The meeting of mediative disciplines and Western psychology: A mutually enriching dialogue. American Psychologist, 61, 690701.

Zaleski, K. (2010). Examining the Effectiveness of Meditation on Well Being in Subjects without any Self-Reported Psychopathology. ProQuest Dissertations and Theses. 